\title{
STUDI REAKSI KOPLING OKTADESILSILAN DENGAN ARIL IODIDA TERSUBSTITUSI PARA
}

\author{
Aldes Lesbani*, Risfidian Mohadi, Nurlisa Hidayati, Elfita \\ Jurusan Kimia FMIPA Universitas Sriwijaya \\ *e-mail : aldeslesbani@yahoo.com
}

\begin{abstract}
ABSTRAK
Telah dilakukan reaksi kopling oktadesilsilan dengan 4-iodida tioanisol dan 4iodida anisol pada posisi para menggunakan katalis paladium dalam kondisi atmosfir argon/nitrogen menghasilkan senyawa tris-(4-tioanisil)-oktadesilsilan (1) dan tris-(4metoksifenil)-oktadesilsilan (2)

Hasil penelitian ini diperoleh senyawa (1) berupa kristal putih dengan titik leleh 59,8-60,5 ${ }^{\circ} \mathrm{C}$ dan puncak ion molekul sebesar $\mathrm{m} / z$ 650 Sedangkan untuk senyawa (2) mempunyai titik leleh $53,5-54,0{ }^{\circ} \mathrm{C}$ dengan nilai $\mathrm{m} / \mathrm{z}$ 602. Karakterisasi menggunakan ${ }^{1} \mathrm{H}$ dan ${ }^{13} \mathrm{C}$ NMR menghasilkan puncak-puncak pergeseran kimia yang menunjukkan senyawa (1) adalah tris-(4-tioanisil)-oktadesilsilan dan senyawa (2) adalah tris-(4-metoksifenil)oktadesilsilan (2).
\end{abstract}

Kata kunci : reaksi kopling, oktadesilsilan, aril iodida

\section{THE COUPLING REACTION STUDY OF OCTADECYLSILANE WITH ARYL IODIDE ON PARA SUBSTITUTION}

\begin{abstract}
Study coupling reaction of octadecylsilane with 4-iodo thioanisole and 4-iodo anisole on para position gave tris-(4-thioanisyl)-octadecylsilane (1) dan tris-(4metoxyphenyl)-octadecylsilane (2) was carried out using palladium catalyst in argon/nitrogen atmosphere.

Compound (1) and (2) are white crystals with melting point $59.8-60.5{ }^{\circ} \mathrm{C}$ and molecular peak ion at $\mathrm{m} / z 650$ for (1), then compound (2) has melting point $53.5-54.0{ }^{\circ} \mathrm{C}$ with $m / z$ 602. Characterization using ${ }^{1} \mathrm{H}$ and ${ }^{13} \mathrm{C}$ NMR shows appropriate chemical shift for compound (1) and (2).

Keywords: coupling reaction, octadecylsilane, aryl iodide

\section{PENDAHULUAN}

Perkembangan reaksi-reaksi kimia dalam rangka sintesis molekulmolekul baru yang berguna bagi kehidupan manusia terus dilakukan hingga sekarang. Salah satu reaksi kimia

yang terus dikembangkan untuk tujuan ini adalah reaksi kopling (Hagedus, 2002). Reaksi kopling merupakan reaksi penggabungan dua molekul atau lebih membentuk molekul baru yang mempunyai sifat yang khas dengan
\end{abstract}


menggunakan bantuan katalis (Tsuji, 2004, Negishi, 2002). Sifat yang khas dapat ditunjukkan dari struktur molekul hasil sintesis dan manfaatnya seperti untuk obat-obatan, pestidida, maupun bagi industri kosmetika dan parfum (Kagechika et al., 2005). Dalam reaksi kopling dibutuhkan suatu katalis yang pada umumnya berasal dari logam-logam transisi atau senyawa-senyawa logam transisi yang merupakan senyawa kompleks (Trost et al., 1982). Selain kegunaan reaksi kopling untuk tujuan diatas, reaksi kopling juga dikembangkan dalam rangka efisiensi sintesis dimana reaksi kopling dapat memperpendek rute sintesis suatu senyawa yang disebabkan oleh penggunaan katalis yang tepat dalam proses reaksinya (Malleron et al., 1997).

$\begin{array}{ccr} & \text { Reaksi kopling yang menarik } \\ \text { untuk } & \text { dipelajari seperti } & \text { reaksi }\end{array}$ organologam grup 14 dengan aril halida (Gilman et al., 1966). Reaksi ini banyak dikembangkan untuk tujuan sintesis molekul baru yang berguna untuk obatobatan, kosmetika, pestisida, maupun sensor (Gross et al., 1997). Lesbani dkk (2010a) telah melakukan sintesis senyawa tris(trimetilsilil)silan. Hasil analisis terhadap senyawa tris(trimetilsilil)silan diketahui bahwa senyawa ini mempunya sifat photoluminescence violet-blue yang khas. Senyawa ini disintesis melalui reaksi kopling menggunakan katalis paladium antara organosilika dengan aril halida dengan kemurnian dan rendemen yang tinggi. Selanjutnya Lesbani dkk (2010b) melaporkan bahwa organologam grup 14 dapat dikopling dengan berbagai aril halida pada temperatur ruang dengan rendemen yang tinggi.

Salah satu contoh aplikasi reaksi kopling organologam grup 14 dengan aril halida telah dilaporkan oleh Lesbani dkk (2012). Organosilika yang merupakan senyawa organologam grup 14 direaksikan dengan aril halida menggunakan katalis paladium untuk menghasilkan senyawa flusilazol. Senyawa flusilazol merupakan senyawa yang banyak dipakai sebagai pestisida dan disintesis dalam beberapa tahap reaksi. Akan tetapi dengan reaksi kopling maka tahap reaksi dapat dipersingkat.

Pada penelitian ini akan dikaji lebih lanjut terhadap reaksi kopling dari berbagai aril halida dengan oktadesilsilan yang merupakan senyawa organologam grup 14. Penggunaan oktadesilsilan dalam reaksi kopling dilaporkan oleh Lesbani dkk (2010b) menggunakan dua aril halida yakni 2-iodo tiophen dan 3iodo thiophen. Pada penelitian ini akan dilaporkan reaksi kopling antara oktadesilsilan dengan 4-iodida tioanisol dan 4-iodida anisol sebagai aril halida dengan katalis paladium.

\section{METODOLOGI PENELITIAN}

\section{Alat dan Bahan}

Alat-alat yang dipergunakan dalam penelitian ini meliputi peralatan gelas kimia seperti labu Schlenk $50 \mathrm{~mL}$, beker gelas, syringe $1 \mathrm{~mL}, 5 \mathrm{~mL}$, dan 10 $\mathrm{mL}$, pengaduk magnetik, pipet tetes, rotary evaporator dengan labu dan pompa vakum. Peralatan analisis yang meliputi NMR Jeol $500 \mathrm{MHz}$ untuk ${ }^{1} \mathrm{H}$ dan $125 \mathrm{MHz}$ untuk ${ }^{13} \mathrm{C}$, GC-MS Shimadzu serta peralatan melting point Fischer Jones.

Bahan-bahan kimia yang
dipergunakan dalam penelitian ini berkualitas analytical grade (p.a) buatan Merck, Aldrich, TCI dan Kanto Jepang dan dipergunakan langsung tanpa pemurnian lebih lanjut yang meliputi asetonitril, metanol, oktadesilsilan, 4iodida anisol, 4-iodida tioanisol, tetrahidrofuran (THF), 1,4diazabisiklo[2,2,2]oktan (DABCO), pelat kromatografi lapis tipis (KLT), silika gel, paladium tersier tributil fosfin, gas argon, 
gas nitrogen, dan akuades.

\section{Prosedur Penelitian}

\section{Sintesis tris-(4-tioanisil)-oktadesilsilan}

(1) dan tris-(4-metoksifenil)-

\section{oktadesilsilan (2)}

Studi reaksi kopling oktadesilsilan dengan aril iodida (4iodida tioanisol atau 4-iodida anisol) dilakukan dalam labu Schlenk $50 \mathrm{~mL}$ yang dilengkapi dengan pengaduk magnetik dengan kondisi atmosfir argon atau nitrogen. Sebanyak $0,05 \mathrm{mmol}$ paladium tersier tributil fosfin sebagai katalis, 1 mmol oktadesilsilan, $5 \mathrm{mmol}$ DABCO sebagai basa, dan $4 \mathrm{mmol}$ aril iodida dimasukkan dalam labu Schlenk yang telah divakum selama 30 menit. Selanjutnya tetrahidrofuran sebanyak 3 $\mathrm{mL}$ dimasukkan ke dalam labu dengan menggunakan syringe secara perlahan.

Reaksi diaduk dengan pengaduk magnetik dan pembentukan produk dimonitoring menggunakan teknik kromatografi lapis tipis (KLT) dalam interval waktu tertentu. Setelah pembentukan produk maka reaksi dihentikan dengan penambahan air 10 $\mathrm{mL}$ ke dalam campuran reaksi. Larutan dipindahkan dalam corong pisah dan ditambahkan diklorometan yang dilanjutkan dengan proses ekstraksi. Proses pemisahan produk dilakukan setelah didapat ekstrak pekat melalui kromatografi kolom untuk didapatkan kristal murni. Proses rekristalisasi dilakukan menggunakan pelarut metanol untuk senyawa (1) dan asetonitril untuk senyawa (2) dengan cara melarutkan kristal menggunakan pelarut dan dipanaskan. Kristal murni diperoleh setelah proses pendinginan. Produk reaksi kopling dikarakterisasi menggunakan GC-MS, ${ }^{1} \mathrm{H}$ NMR, ${ }^{13} \mathrm{C}$ NMR serta penentuan titik leleh.

\section{HASIL DAN PEMBAHASAN}

Reaksi kopling oktadesilsilan dengan 4-iodida tioanisol maupun dengan 4-iodida anisol dengan katalis paladium tersaji pada Skema 1.

Oktadesilsilan merupakan organosilika primer dengan tiga atom hidrogen yang terikat didalamnya. Ketiga atom hidrogen tersebut digantikan oleh senyawa aril melalui substitusi dengan reaksi kopling menggunakan paladium sebagai katalis. Reaksi ini ditujukan untuk mencari keragaman senyawa organosilika. Organosilika merupakan salah satu senyawa organologam yang penting bagi industri, kesehatan, dan rumah tangga (Daiss et al., 2005).

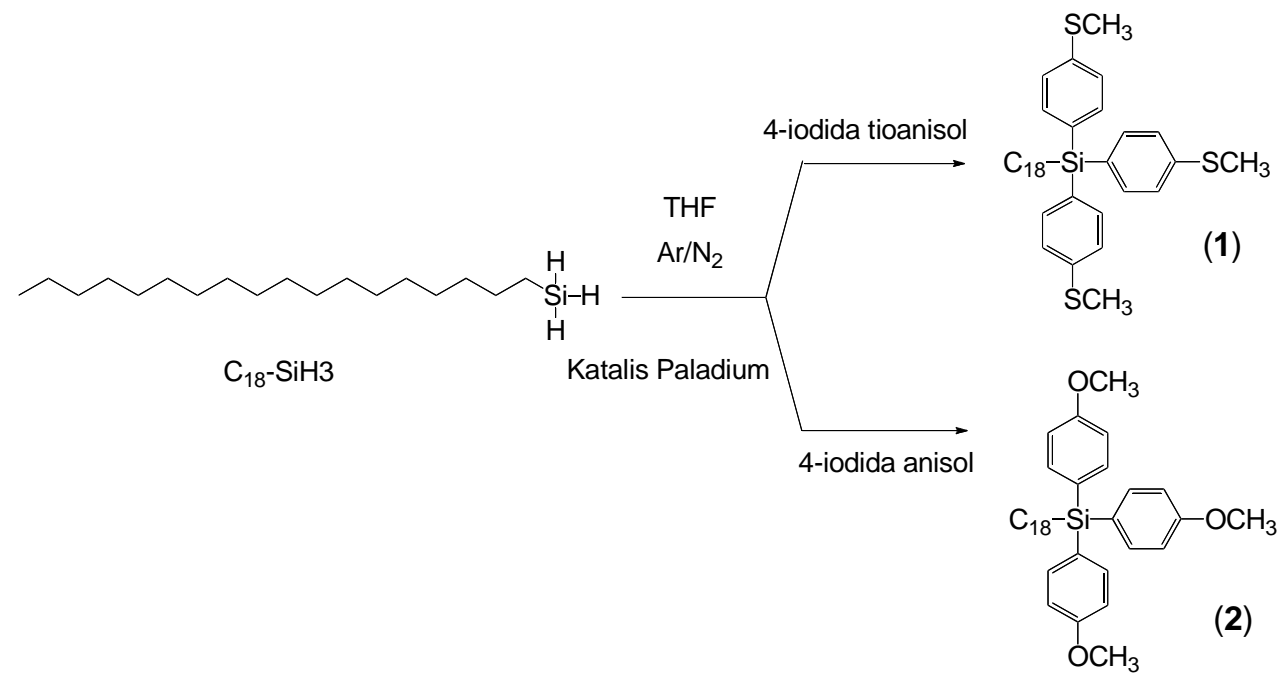

Skema 1. Reaksi kopling oktadesilsilan dengan aril iodida. 
Pada reaksi kopling seperti yang tersaji pada Skema 1 diatas, senyawa hasil reaksi kopling yakni senyawa (1) dan senyawa (2) merupakan kristal putih yang diperoleh dari proses pemisahan menggunakan kromatografi kolom silika. Kristal yang diperoleh direkristalisasi menggunakan metanol untuk senyawa (1) dan asetonitril untuk senyawa (2). Kristal hasil rekristalisasi ditimbang dan didapat rendemen untuk senyawa (1) sebesar $20 \%$ dan senyawa (2) sebesar 39\%. Rendemen hasil sintesis senyawa (1) dan (2) pada reaksi kopling ini sangat rendah bila dibandingkan dengan reaksi kopling yang telah dilakukan oleh Lesbani et al. (2010b). Murata et al. (2002) melaporkan bahwa reaksi kopling antara trietoksisilan dan aril halida menghasilkan rendemen yang tinggi. Produk reaksi kopling seperti yang tersaji pada Skema 1 mempunyai rendemen yang rendah dapat dipahami karena oktadesilsilan yang memiliki rantai karbon yang panjang (C-18) sehingga substitusi aril halida sedikit mendapat halangan ruang (steric factor) walaupun aril iodida yang digunakan memiliki substituent pada posisi para (Solomons et al., 2008). Produk (1) dan (2) ditentukan titik lelehnya menggunakan melting point dan diperoleh titik leleh senyawa (1) sebesar 59,8-60,5 ${ }^{\circ} \mathrm{C}$ dan senyawa (2) sebesar $53,5-54,0{ }^{\circ} \mathrm{C}$.

Senyawa (1) dan (2) hasil reaksi kopling selanjutnya dikarakterisasi menggunakan gas kromatografispektrometer massa (GC-MS), spektrometer NMR ${ }^{1} \mathrm{H}$ dan ${ }^{13} \mathrm{C}$. Hasil analisis GC-MS terhadap senyawa (1) dan (2) disajikan pada Gambar 1. Dari spektra massa senyawa (1) dan (2) seperti yang tersaji pada Gambar 1 terlihat bahwa senyawa (1) memiliki puncak ion molekul pada $\mathrm{m} / z 650$ dan senyawa (2) pada $m / z$ 602. Puncak ion molekul yang terukur pada senyawa (1) dan (2) tersebut sesuai dengan bobot molekul yang dimiliki oleh senyawa (1) dan (2) sesuai dengan struktur pada Skema 1 diatas. Fragmentasi molekul senyawa (1) dan (2) memiliki pola yang berbeda walaupun struktur yang dimilikinya mempunyai kemiripan yang hanya dibedakan oleh gugus metoksi dan gugus tioanisol. Selanjutnya dilakukan karakterisasi terhadap senyawa (1) dan (2) menggunakan ${ }^{1} \mathrm{H}$ dan ${ }^{13} \mathrm{C} \quad \mathrm{NMR}$ menggunakan pelarut $\mathrm{CDCl}_{3}$. Spektrum ${ }^{1} \mathrm{H}$ dan ${ }^{13} \mathrm{C}$ NMR senyawa (1) dan (2) disajikan pada Gambar 2 dan 3.
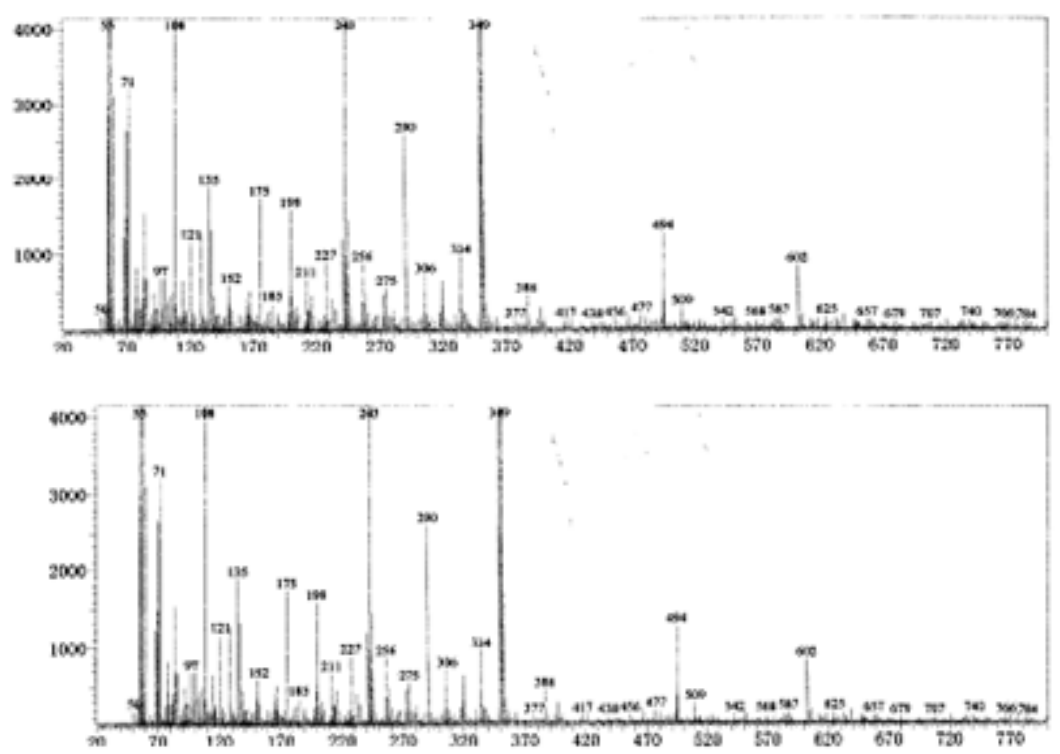
Gambar 1. Spektra massa senyawa (1) (atas) dan (2) (bawah).
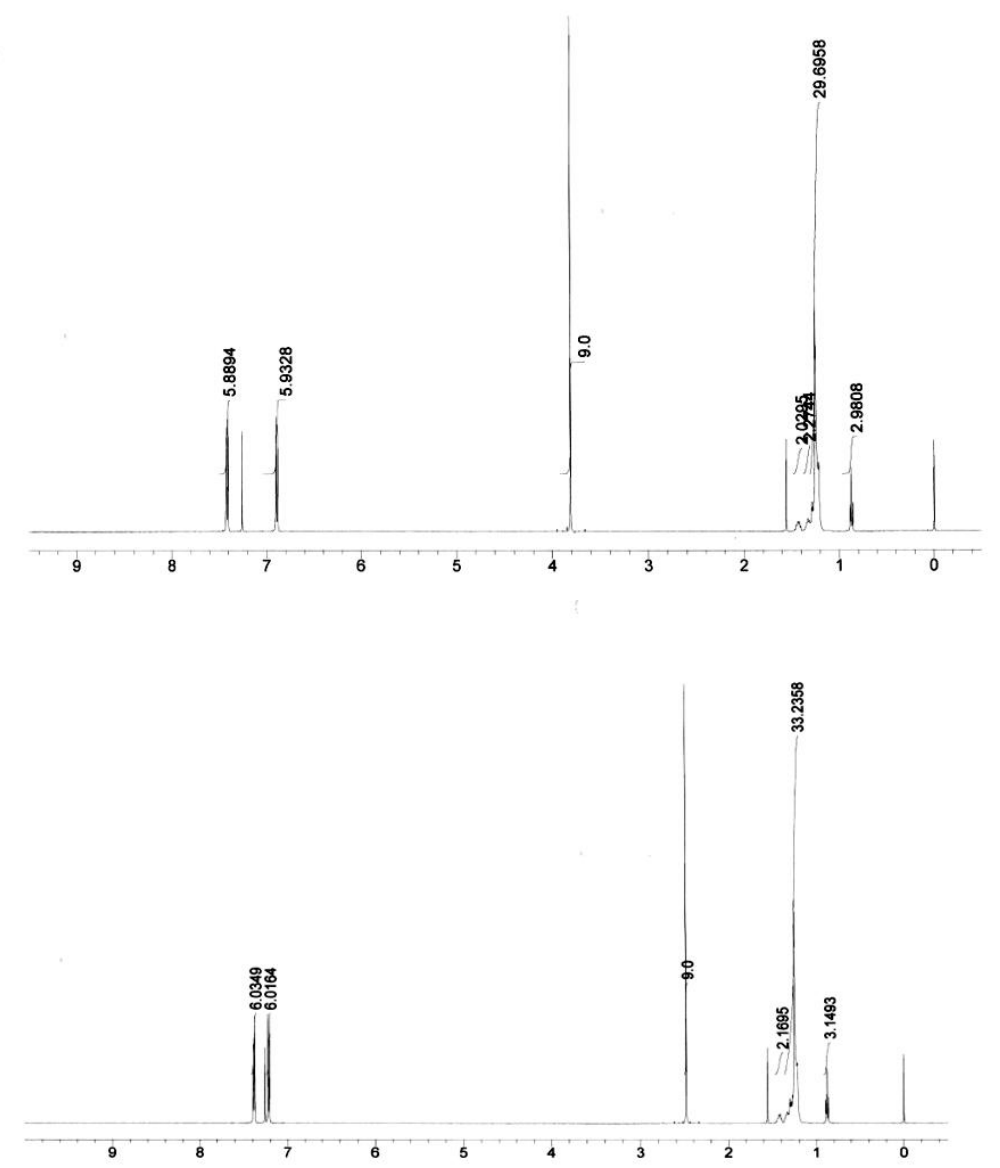

Gambar 2. Spektrum ${ }^{1} \mathrm{H}$ NMR $500 \mathrm{MHz}$ senyawa (1) (atas) dan (2) (bawah) dengan pelarut $\mathrm{CDCl}_{3}$.

Pada Skema 1 terlihat bahwa senyawa (1) dan (2) memiliki total jumlah proton yang sama yakni 59 buah. Sebaran proton tersebut yakni 38 buah proton pada rantai alifatik, 12 buah proton pada cincin aromatik dan 9 buah proton pada substituen aromatik. Pada Gambar 2 yang menunjukkan spektrum ${ }^{1} \mathrm{H}$ NMR senyawa (1) dan (2) terlihat bahwa terdapat total proton masing masing berjumlah 59 buah. Hal ini bersesuaian dengan jumlah proton yang terdapat pada struktur senyawa (1) dan (2). Masingmasing sebaran proton tersebut yakni $\delta$ $0.88 \mathrm{ppm}(\mathrm{t}, 3 \mathrm{H}, J=7.0 \mathrm{~Hz}), 1,28 \mathrm{ppm}$ $(\mathrm{m}, 33 \mathrm{H}), 1,41 \mathrm{ppm}(\mathrm{m}, 2 \mathrm{H}), 2,48 \mathrm{ppm}$ (s, 9H), 7,22 ppm (d, 6H, $J=8,1 \mathrm{~Hz})$, 7,38 ppm (d, 6H, $J=8,1 \mathrm{~Hz})$ untuk senyawa (1) dan $\delta 0,88 \mathrm{ppm}(\mathrm{t}, 3 \mathrm{H}, J=$ 7,0 Hz), 1,28 ppm (m, 33H), 1,43 ppm $(\mathrm{m}, 2 \mathrm{H}), 3,81 \mathrm{ppm}(\mathrm{s}, 9 \mathrm{H}), 6,89 \mathrm{ppm}(\mathrm{d}$, $6 \mathrm{H}, J=8,6 \mathrm{~Hz}), 7,41 \mathrm{ppm}(\mathrm{d}, 6 \mathrm{H}, J=8,6$ $\mathrm{Hz}$ ) untuk senyawa (2). Sebaran proton pada senyawa (1) dan (2) terlihat memiliki kemiripan pada rentang pergeseran kimia 0-2 ppm dan 6-8 ppm. Daerah tersebut identik dengan sebaran proton pada gugus alifatik dan aromatik (Clayde et al., 2008). Sedangkan proton pada substituent aromatik yakni $-\mathrm{OCH}_{3}$ dan $-\mathrm{SCH}_{3}$ memiliki pergeseran kimia yang sedikit berbeda yakni 2,48 ppm 
untuk $-\mathrm{SCH}_{3}$ dan 3,81 ppm untuk $-\mathrm{OCH}_{3}$. Fenomena ini mirip dengan perbedaan pola fragmentasi dari senyawa (1) dan (2).

Pada spektrum ${ }^{13} \mathrm{C}$ NMR seperti yang tersaji pada Gambar 3 terlihat bahwa senyawa (1) memiliki puncak pada pergeseran kimia $\delta$ 13,2 ppm $\left(\mathrm{CH}_{3}\right), 14,1 \mathrm{ppm}\left(\mathrm{CH}_{2}\right), 15,1 \mathrm{ppm}\left(\mathrm{CH}_{3}\right)$, 22,7 ppm $\left(\mathrm{CH}_{2}\right), 23,9$ ppm $\left(\mathrm{CH}_{2}\right), 29,0$ ppm $\left(\mathrm{CH}_{2}\right), 29,4$ ppm $\left(\mathrm{CH}_{2}\right), 29,6$ ppm $\left(\mathrm{CH}_{2}\right), 30,0 \mathrm{ppm}\left(\mathrm{CH}_{2}\right), 31,9 \mathrm{ppm}\left(\mathrm{CH}_{2}\right)$, $33,8 \mathrm{ppm}\left(\mathrm{CH}_{2}\right), 125,3 \mathrm{ppm}(\mathrm{CH}), 131,0$ ppm (Cq), 136,2 ppm (CH), dan 140,3 ppm (Cq). Senyawa (2) memiliki puncak pada pergeseran kimia $\delta 13,8 \mathrm{ppm}\left(\mathrm{CH}_{3}\right)$, $14,1 \mathrm{ppm}\left(\mathrm{CH}_{2}\right), 22,7 \mathrm{ppm}\left(\mathrm{CH}_{2}\right), 24,0$ ppm $\left(\mathrm{CH}_{2}\right)$, 29,2 ppm $\left(\mathrm{CH}_{2}\right), 29,4$ ppm $\left(\mathrm{CH}_{2}\right), 29,6 \mathrm{ppm}\left(\mathrm{CH}_{2}\right), 29,7 \mathrm{ppm}\left(\mathrm{CH}_{2}\right)$, 31,9 ppm $\left(\mathrm{CH}_{2}\right), 33,9$ ppm $\left(\mathrm{CH}_{2}\right), 55,0$ ppm $\left(\mathrm{CH}_{3}\right), 113,5$ ppm $(\mathrm{CH}), 126,9 \mathrm{ppm}$ (Cq), 137,0 ppm (CH), dan 160,5 ppm (Cq). Secara keseluruhan baik senyawa (1) maupun senyawa (2) memiliki 15 puncak pada spektrum ${ }^{13} \mathrm{C}$ NMR dengan jumlah 2 puncak $\mathrm{CH}_{3}, 9$ puncak $\mathrm{CH}_{2}, 2$ puncak $\mathrm{CH}$ dan 2 puncak Cq. Perbedaan tampak pada pergeseran kimia $-\mathrm{CH}_{3}$ yang diakibatkan $-\mathrm{CH}_{3}$ yang terikat pada $\mathrm{S}$ pada senyawa (1) serta $\mathrm{O}$ pada senyawa (2). Dari hasil pengukuran menggunakan ${ }^{1} \mathrm{H}$ dan ${ }^{13} \mathrm{C}$ NMR dapat dipastikan bahwa senyawa (1) dan (2) telah berhasil disintesis dengan reaksi kopling menggunakan katalis paladium.
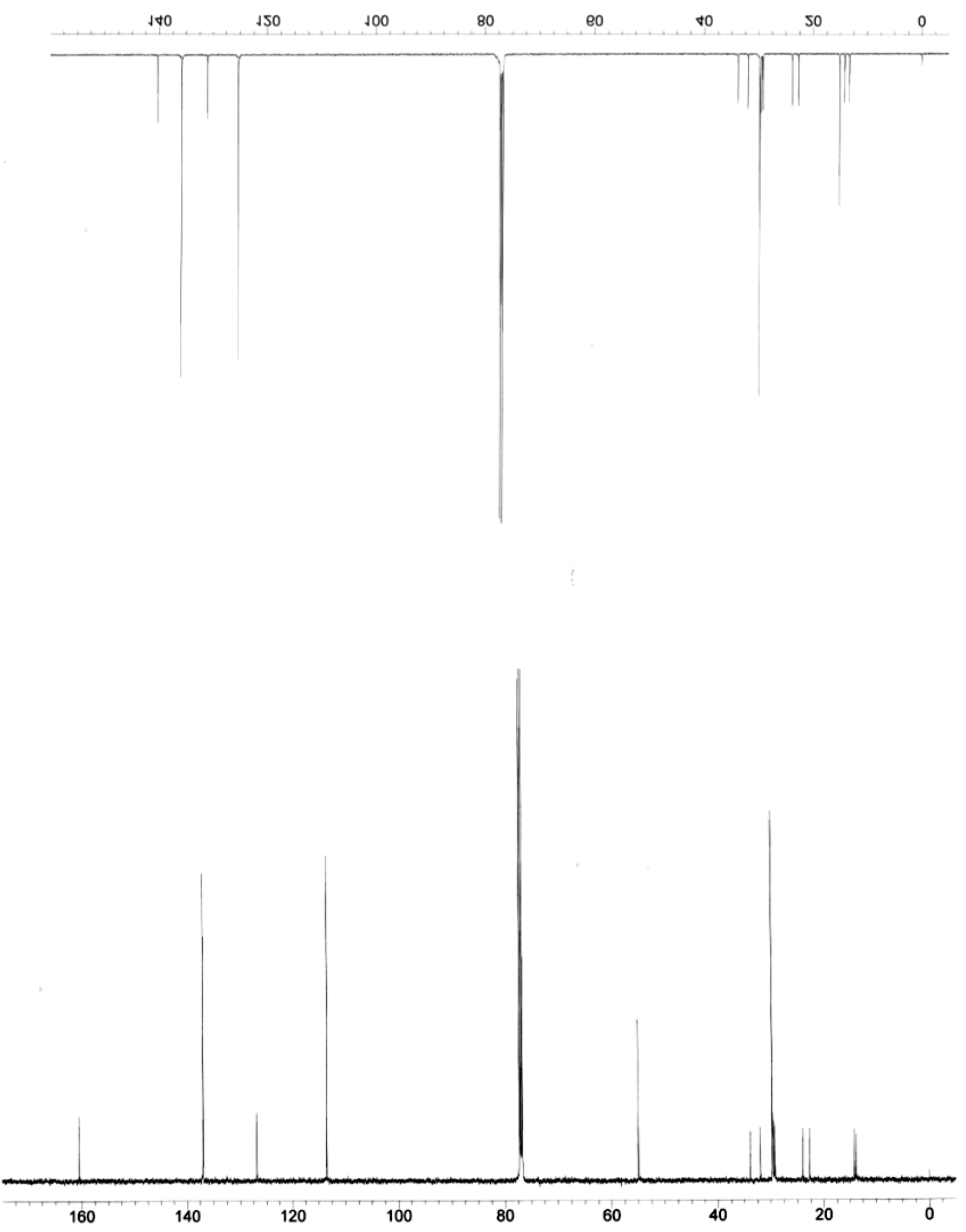

Gambar 3. Spektrum ${ }^{13} \mathrm{C}$ NMR $125 \mathrm{MHz}$ senyawa (1) (atas) dan (2) (bawah) dengan 


\section{KESIMPULAN}

\begin{abstract}
Senyawa
oktadesilsilan

(1)

tris-(4-tioanisil)metoksifenil)-oktadesilsilan (2) dapat disintesis dari reaksi kopling oktadesilsilan dengan 4-iodida tioanisol dan 4-iodida anisol menggunakan katalis paladium. Senyawa (1) dan (2) berupa kristal putih dengan kemurnian yang tinggi yang ditunjukkan dari data GCMS, ${ }^{1} \mathrm{H}$ dan ${ }^{13} \mathrm{C}$ NMR. tris-(4-tioanisil)oktadesilsilan (1) memiliki rendemen sebesar 20\% dan tris-(4-metoksifenil)oktadesilsilan (2) sebesar 39\%.
\end{abstract}

\section{DAFTAR PUSTAKA}

Clayden, Greeves, Warren, Wothers, 2008, Organic Chemistry, Oxford University Press, Oxford, UK.

Daiss. J.O, Burschka. C, Mills. J. S, Montana. J. G, Showell. G. A, Fleming. I, Gaudon. C, Ivanona. D, Gronemeyer. H, Tacke. R, 2005, Synthesis, Crystal Structure Analysis, and Pharmacological Characterization of Disilabexarotene, a Disila-Analogue of the RXR-Selective Retinoid Agonist Bexarotene, Organometallics, 24, 3192-3199.

Gilman. H, Harrell. R. L, 1966, Highly Branched-Chain Methylhalo Polysilanes, Journal of Organometallic Chemsitry, 5, 199-200.

Gross. T, Kempe. R, Oehme. H, 1997, 1,2-Di(hypersilyl)-ethylene-

TheUnpexpected Result of The Reaction of Tris(trimethylsilyl)Silyllithium With Formic Acid Methyl Ester, Journal of Organometallic Chemistry, 534, 229-231.
Hegedus. L. S, 2002, Organometallics in Synthesis, Chichester: Wiley.

Kagechika. H, Shudo. K, 2005, Synthetic Retinoids: Recent Developments Concerning Structure and Clinical Utility, Journal of Medicinal Chemistry, 48, 19, 5875-5883.

Lesbani. A, Kondo. H, Sato J. I, Yamanoi. Y, Nishihara. H, 2010a, Facile Synthesis of Hypersilylated Aromatic Compounds by Palladium-Mediated Arylation Reaction, Chemical Communications, 46, 7784-7786.

Lesbani. A, Kondo. H, Yabusaki. Y, Nakai. M, Yamanoi. Y, Nishihara. $\mathrm{H}, 2010 \mathrm{~b}$, Integrated PalladiumCatalyzed Arylation of Heavier Group 14 Hydrides, Chemistry A European Journal, 16, 1351913527.

Lesbani. A, Kondo. H, Yamanoi. Y, Nishihara. N, 2012, Sintesis Pestisida Flusilazol, Jurnal Kimia FMIPA Universitas Udayana, 6, 1-7.

Malleron. J, Fiaud. J, Legros. J, 1997, Handbook of PalladiumCatalyzed Organic Reactions, Academic Press, San Diego.

Murata. M, Ishikura. M, Nagata. M, Watanabe. S, Masuda. Y, 2002, Rhodium(I)-Catalyzed Silylation of Aryl Halides With Triethoxysilane: Practical Synthetic Route to Aryltriethoxysilanes, Organic Letters, 4,11, 1843-1845.

Negishi. E, 2002, Organopalladium Chemistry, New York: WileyInterscience.

Solomons. T.W.G, Fryhle. C.B, 2008, Organic Chemistry, 9th Edition, John Wiley \& Sons, Inc, USA. 
Studi Reaksi Kopling Oktadesilsilan dengan Aril Iodida ... (Aldes Lesbani, dkk.) 
Molekul, Vol. 8. No. 1. Mei, 2013: 58 - 65

Trost. B. M, Verhoeven. T. R, 1982,

Tsuji. J, 2004, Palladium Reagents and Comprehensive Organometallic

Chemistry, Pergamon, Oxford,

Catalyst, Chichester: Wiley.

UK. 